|| ISSN(online): 2589-8698 || ISSN(print): 2589-868X || International Journal of Medical and Biomedical Studies

Available Online at www.ijmbs.info

PubMed (National Library of Medicine ID: 101738825)

Index Copernicus Value 2018: 75.71

Original Research Article

Volume 3, Issue 6; June: 2019; Page No. 237-240

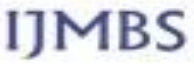

TO STUDY THE CLINICAL PROFILE OF CHILDREN (AGED 1MONTH-14YRS) SUFFERING FROM URINARY TRACT INFECTION

\title{
Dr. Moti Lal Soni
}

MD Paeditrics, Senior Resident, Pandit Deendayal Upadhyaya Medical College, Churu, Rajasthan.

Article Info: Received 25 May 2019; Accepted 24 June. 2019

DOI: https://doi.org/10.32553/ijmbs.v3i6.342

Address for Correspondence: Dr. Moti Lal Soni

Conflict of interest: No conflict of interest.

\section{Abstract}

Background: Urinary tract infections (UTIs) are common bacterial infections in children. The diagnosis of UTI is very often missed in young children due to minimal and nonspecific symptoms.

Methods: Hospital based observational prospective study conducted 100 clinical cases.

Results: According to presenting history, maximum patients presented with abdominal symptoms (72\%), urinary symptoms (23.0\%), followed by respiratory symptoms in $18.0 \%$ cases, CNS symptoms (8.0\%) and non-specific symptoms in $47.0 \%$ cases. Fever was the most common presenting complaint followed by vomiting, pain abdomen, oliguria, Diarrhoea, generalized swelling, burning micturition, cough, decreased appetite, respiratory distress, excessive cry, chills and rigor, abnormal body movement, yellow colour of urine, headache while least common present history was chest pain and joint swelling where 1 case each was found.

Conclusion: UTI is a common childhood illness. Females were more commonly affected than males. Fever being most common presenting symptom followed by vomiting and pain abdomen.

Keywords: Urinary tract infections (UTIs), Females, Fever.

\section{Introduction}

Urinary tract infections (UTIs) are common bacterial infections in children. The diagnosis of UTI is very often missed in young children due to minimal and nonspecific symptoms. The developing renal cortex in young children is vulnerable to renal scarring resulting in hypertension and chronic renal failure. These morbidities in adults often have their origin in childhood. A clinically suspected case of UTI should be defined and documented with urine culture report. After the diagnosis of UTI, its category should be defined. This helps in guiding a clinician about the appropriate radio/nuclear imaging evaluation, choice of antimicrobial agent, duration of treatment and need of chemoprophylaxis. Even a single confirmed UTI should be taken seriously ${ }^{1}$.

The risk of having a UTI before the age of 14 years is approximately $1-3 \%$ in boys and $3-10 \%$ in girls. Complications include renal parenchymal damage and renal scarring that can lead to hypertension and progressive renal insufficiency in later life. In children, UTI may be the first presentation of an underlying congenital anomaly of the urinary tract. Therefore rapid diagnosis, institution of early treatment and further evaluation by imaging modalities is important to preserve the function of the growing kidney ${ }^{2}$.

Etiological agents of UTI are variable and usually depend on time, geographical location and age of patients. However, Escherichia coli, Proteus mirabilis, Enterobacter agglomerans, Citrobacter freundii and Klebsiella pneumonia account for over $70 \%$ of cases ${ }^{3-}$ 5 .

The aim of present study was to record the common clinical presentation of UTI at Tertiary level care Hospital.

\section{MATERIALS AND METHODS}

Study design: Hospital based observational prospective study.

Sample size: Total 100 clinical cases were included.

Sampling Method: Random sampling.

Inclusion criteria: All children in the age group of 1month to14 years admitted in hospital with a 
probable diagnosis of urinary tract infection that is later confirmed by a positive urine culture.

Exclusion criteria: Infants below 1 month old were excluded.

Data Collection: Patients from the age of 1 month to 14 years presenting with urinary symptoms (dysuria, urgency, frequency, incontinence, hematuria and suprapubic pain) and those with fever without focus were enrolled in the study. History was noted and children clinically examined. Complicated UTI (involvement of upper urinary tract) was diagnosed if there was presence of any one or all of the followingfever $>39^{\circ} \mathrm{C}$, systemic toxicity, persistent vomiting, dehydration, renal angle tenderness and raised serum creatinine. Recurrent UTI was considered if there was a previous history of one or more episodes of proven UTI.

Data Analysis:

To collect required information from eligible patients a pre-structured pre-tested Proforma was used. For data analysis statistical software SPSS was used and data were analyzed with the help of frequencies, figures, proportions, measures of central tendency, appropriate statistical test.

\section{OBSERVATIONS}

Table 1: Distribution of cases according to age

\begin{tabular}{|l|l|l|}
\hline \multirow{2}{*}{ Age Group (years) } & \multicolumn{2}{|l|}{ Total } \\
\cline { 2 - 3 } & No. & $\%$ \\
\hline$<1$ & 14 & 14.0 \\
\hline $1-5$ & 40 & 40.0 \\
\hline $6-10$ & 28 & 28.0 \\
\hline$>10$ & 18 & 18.0 \\
\hline Total & 100 & 100 \\
\hline
\end{tabular}

In present study, out of total 100 cases, majority of cases were between 1 to 5 years (40\%) followed by 6 10 years $(28 \%)$, more than 10 years $(18 \%)$ and less than 1 year (14\%).

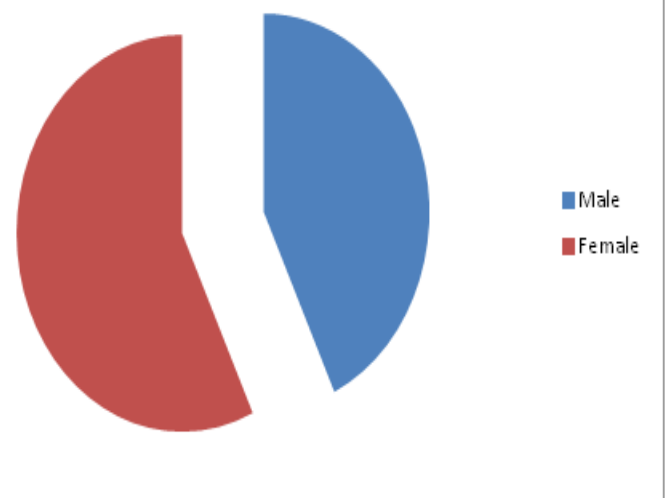

Female were more affected than male children.

Table 2: Distribution of cases according to socioeconomic status

\begin{tabular}{|l|l|l|}
\hline Socioeconomic Status & No. of Cases & $\%$ \\
\hline Lower & 4 & 4.0 \\
\hline Lower Middle & 22 & 22.0 \\
\hline Middle & 31 & 31.00 \\
\hline Upper Middle & 26 & 26.0 \\
\hline Upper & 17 & 17.0 \\
\hline Total & 100 & 100 \\
\hline
\end{tabular}

Out of total 100 cases, majority of patients i.e. $31.0 \%$ were from middle socioeconomic status followed by $26.00 \%$ belonged to upper middle socioeconomic status, $22.00 \%$ cases belonged to lower middle socioeconomic status.

Table 3: Clinical distribution of cases according to present history

\begin{tabular}{|l|l|l|}
\hline Present History & No. of Cases & $\%$ \\
\hline Fever & 60 & 60.00 \\
\hline Abdominal Symptoms & & \\
\hline Vomiting & 32 & 32.0 \\
\hline Pain abdomen & 24 & 24.0 \\
\hline Diarrhoea & 12 & 12.00 \\
\hline Constipation & 2 & 2 \\
\hline Urinary Symptoms & & \\
\hline Oliguria & 22 & 22.0 \\
\hline Burning Micturition & 12 & 12.00 \\
\hline Yellow Colour of Urine & 4 & 4.00 \\
\hline Frequent Urination & 3 & 3.00 \\
\hline Haematuria & 3 & 3.00 \\
\hline Respiratory Symptoms & & \\
\hline Cough & 10 & 10.0 \\
\hline Respiratory Distress & 7 & 7.0 \\
\hline
\end{tabular}




\begin{tabular}{|l|l|l|}
\hline CNS Symptoms & & \\
\hline Abnormal Body Movement & 5 & 5.00 \\
\hline Altered Sensorium & 2 & 2.0 \\
\hline Vertigo & 2 & 2.0 \\
\hline Non-Specific & & \\
\hline Generalized Swelling & 14 & 14.0 \\
\hline Decreased Appetite & 8 & 8.0 \\
\hline Excessive Cry & 7 & 7.0 \\
\hline Chills \& Rigor & 6 & 6.0 \\
\hline Headache & 4 & 4.0 \\
\hline Groin Pain & 3 & 3.00 \\
\hline Nausea & 2 & 2.00 \\
\hline Not Gaining Weight & 2 & 2.00 \\
\hline Skin Lesion & 2 & 2.00 \\
\hline Leg Pain & 1 & 1.00 \\
\hline Chest Pain & 1 & 1.00 \\
\hline Joint Swelling & 1 & 1.00 \\
\hline
\end{tabular}

According to presenting history, maximum patients presented with abdominal symptoms $(72 \%)$, urinary symptoms (23.0\%), followed by respiratory symptoms in $18.0 \%$ cases, CNS symptoms (8.0\%) and non-specific symptoms in $47.0 \%$ cases. Fever was the most common presenting complaint followed by vomiting, pain abdomen, oliguria, Diarrhoea, generalized swelling, burning micturition, cough, decreased appetite, respiratory distress, excessive cry, chills and rigor, abnormal body movement, yellow colour of urine, headache while least common present history was chest pain and joint swelling where 1 case each was found.

\section{DISCUSSION}

UTI was more common in children of 1-5 age groups. Ineffective toilet training and the resultant ascending infection from urethra may be predisposing children of this age group for UTI. In consensus statement of Indian Pediatric Nephrology Group, it has been mentioned that during the first year of life, male were more effected, beyond 1-2years, there is female preponderance with male.

Taneja et $\mathrm{al}^{5}$ also found maximum number $38.7 \%$ cases between $1-5$ year, $35.7 \%$ of cases were between 5-12 year. They also found male predominance in infancy, which correlate with our study. Sharma et $\mathrm{al}^{6}$ in his study found $50.0 \%$ of cases in age group of 1 to 5 years followed by $27.5 \%$ of cases between 6 to 10 year. In the study by Krishnan et $\mathrm{al}^{7} \mathrm{UTI}$ was more common in children of 1-5 age groups (35.5\%), which was in concordance with our study, they also found male predominance below 1 year.

Female are more likely than male to get UTI because urethra is shorter in female so bacteria can reach the bladder more easily. Due to longer course of urethra and the bacteriostatic action by prostatic secretions in them, the incidence of UTI is low in male.

Badhan et $\mathrm{al}^{7}$ observed that majority of pathogens were isolated from female $(54.2 \%)$ patients. AlMardeni et al ${ }^{8}$ observed that out 529 culture positive culture 432 (81.7\%) were female.

However unlike to our study, Kalantar et $\mathrm{al}^{9}$ in his prospective study of 1696 children aged up to 5 years reported male to female ratio of 1.07:1.

In our study Out of total 100 cases, majority of patients i.e. $31.0 \%$ were from middle socioeconomic status followed by $26.00 \%$ belonged to upper middle socioeconomic status, $22.00 \%$ cases belonged to lower middle socioeconomic status according to modified B.G. Prasad scale.

In a study by Rao et a ${ }^{10}$ most of the cases were from lower classes with $76.6 \%$ and $23.3 \%$ incidence in middle class, which is not in concordance with our study.

In our study According to presenting history, maximum patients presented with abdominal symptoms (72\%), urinary symptoms (23.0\%), followed by respiratory symptoms in $18.0 \%$ cases, CNS symptoms (8.0\%) and non-specific symptoms in $47.0 \%$ cases. Fever was the most common presenting complaint followed by vomiting, pain abdomen, oliguria, Diarrhoea, generalized swelling, burning micturition, cough, decreased appetite, respiratory distress, excessive cry, chills and rigor, abnormal body movement, yellow colour of urine, headache while least common present history was chest pain and joint swelling where 1 case each was found.

In a study by Badhan et $\mathrm{al}^{8}$, presenting symptoms were urinary symptoms alone in $29.2 \%$, fever without urinary symptoms in $23.1 \%$, fever with urinary symptoms $18.7 \%$, pain abdomen in $23.3 \%$.

In studies conducted by other authors Sharma et $\mathrm{al}^{6}$ $(65.0 \%)$, Krishnan et $\mathrm{al}^{7}$ shows fever was seen in majority of patients.

\section{CONCLUSION}

UTI is a common childhood illness. This study shows age and gender distribution in accordance to 
available literature. Females were more commonly affected than males. Fever being most common presenting symptom followed by vomiting and pain abdomen.

\section{BIBLIOGRAPHY}

1. Prajapati BS, Prajapati RB, Patel PS. Advances in management of urinary tract infections. Indian J Pediatr 2008;75:809-14.

2. Shaikh $\mathrm{N}$, Morone $\mathrm{NE}$, Bost JE, Farell $\mathrm{MH}$. Prevalence of urinary tract infection in childhood: A meta-analysis. PaediatrInfec Dis J 2008;27:302-8.

3. Wald ER, Feigin RD, Chery JD, Demmier GJ, Kapian SL. Cystitis and pyelonephritis. Textbook of Pediatric Infectious Diseases. 5th ed. Philadelphia: Saunders ; 2004. p. 541-53.

4. Mashouf RY, Babalhavaeji H, Yousef J. Urinary tract infections: Bacteriology and antibiotic resistance patterns. Ind Pediatr 2009; 46:617-20.

5. Taneja N, Chatterjee SS, Singh M, Singh S, Sharma M. Pediatric urinary tract infection in a tertiary care centre from north India. Indian J Med Res 2010; 131: 101-5.
6. Sharma A, Shrestha S, Upadhyay S, Rijal P. Clinical and bacteriological profile of urinary tract infection in children at Nepal Medical College Teaching Hospital. Nepal Med Coll J. 2011; 13(1):24-6.

7. Krishnan C, Gireeshan VK, Nimmi EJ, et al. Clinico-bacteriological profile of urinary tract infections in children and resistance pattern of uropathogens- A study from south India. J. Evid. Based Med. Healthc. 2017; 4(15), 859-863.

8. Badhan $R$, Singh DV, Badhan LR, Kaur A. Evaluation of bacteriological profile and antibiotic sensitivity patterns in children with urinary tract infection: A prospective study from a tertiary care center. Ind J Urol 2016; 32:50-6.

9. Kalantar $\mathrm{E}$, Motlagh $\mathrm{ME}$, Lornejad $\mathrm{H}$, Reshadmanesh N. Prevalence of urinary tract pathogens and antimicrobial susceptibility patterns in children at hospitals in Iran. Iranian J Clin Inf Dis 2008;3(3):149-53.

10. Rao KR, Gandhi SS, Kokiwar PR. Clinical study of urinary tract infection in children. Int J Contemp Pediatr 2016;3:214 